\title{
Comparative Study between Simple Percutaneous Transluminal Angioplasty and Drug-Coated Balloons in Chronic Total Occlusion of The Femoro-popliteal Artery Emad El-dien Ahmed Hussein ${ }^{1}$, Mohammed Ahmed Mohammed Ismail ${ }^{2}$, Ali Mahmoud Mohammed Galal ${ }^{2}$, Ahmed Khalf Fathy*2 \\ ${ }^{1}$ Department of Vascular Surgery, Faculty of Medicine, Ain Shams University, Cairo, ${ }^{2}$ Department of Vascular Surgery, Faculty of Medicine, Aswan University, Aswan, Egypt \\ *Corresponding author: Ahmed Khalf Fathy, Mobile: (+20) 01063454956, E-Mail: dr_a_khalf1986@yahoo.com
}

\begin{abstract}
Background: Atherosclerotic peripheral artery disease (PAD) affects a growing number of patients in aging populations. Peripheral artery disease (PAD) accounts for a large proportion of cardiovascular disease (CVD) prevalence in most world regions.

Objective: This study aims to evaluate and compare the patency, clinical outcome, and limb salvage rates between the simple percutaneous Transluminal angioplasty and the drug-coated balloons in chronic total occlusion of the femoropopliteal arterial segment on the short-term course.

Patients and Method: A prospective randomized controlled comparative study was conducted in the vascular surgery department; Aswan University Hospital during the period from March 2018 to March 2020. In total, 30 patients with a well-established diagnosis of superficial femoral artery (SFA) and/or proximal popliteal lesions with symptoms of PAD.

Results: The primary patency at 12-month following treatment with DCB was significantly better $100 . \%, 80.0 \%$, $60.0 \%$ at 1, 6, 12 months compared with POBA $86.7 \%, 66.7 \%, 46.7 \%$ at 1, 6, 12 months. The rate of clinicallydriven TLR was the same in both groups $(26.6 \%)$. The use of DCB was safe and did not increase the major adverse clinical events (death, myocardial infarction, and minor or major amputation) when compared with those seen with the use of the uncoated balloons).

Conclusion: Use of DCBs is associated with improved vessel patency when compared to POBA in patients with FPD. There was no difference in clinically driven TLR between DCB and POBA in our study.
\end{abstract}

Keywords: DCB, Patency, Limb Salvage, TLR, POBA

\section{INTRODUCTION}

Endovascular treatment of symptomatic atherosclerotic peripheral arterial disease (PAD) has gained wide-scale acceptance and is now recommended as a primary revascularization strategy in many clinical and anatomical scenarios ${ }^{(\mathbf{1})}$.

In the majority of patients with peripheral arterial disease, the femoropopliteal segment is involved. Guideline recommendations mainly encourage the endovascular as first-line approach ${ }^{(\mathbf{1})}$.

The optimal treatment for superficial femoral (SFA) and popliteal arteries remains controversial. Some practical guidelines advise against primary stenting in patients with intermittent claudication, while others recommend primary stenting in short or intermediate course lesions ${ }^{(2)}$.

However, observational studies raised concerns regarding the risk of stent fracture and significant restenosis due to the unique mechanical forces in the superficial femoral (SFA) and popliteal arteries ${ }^{(3)}$.

Although treatment with Percutaneous Transluminal Angioplasty (PTA) is effective in initially restoring blood flow, restenosis from vessel recoil and neointimal hyperplasia may occur ${ }^{(4)}$.

One approach to this challenge has been the development of drug-coated balloons (DCB) which combines balloon dilatation with local delivery of an anti-proliferative drug to reduce both restenosis and the need for reintervention compared with PTA ${ }^{(5)}$.

DCBs are covered with an anti-proliferative agent, paclitaxel, using urea as an excipient to facilitate the transfer of paclitaxel to the inner vessel surface on balloon inflation. After angioplasty paclitaxel can persist in the vessel wall for up to 180 days in experimental models ${ }^{(6)}$. The IN.PACT SFA study evaluated the IN.PACT Admiral DCB with the area as the excipient of paclitaxel with primary patency of $86.6 \%$ at 12 months ${ }^{(7)}$.

The ILLUMINATE Pivotal Study assessed the Stellarex DCB with paclitaxel and a novel excipient (polyethylene glycol) and showed a patency rate of $89.5 \%$ at 12 months ${ }^{(8)}$.

This study aims to evaluate and compare the patency, clinical outcome, and limb salvage rates between the simple percutaneous Transluminal angioplasty and the drug-coated balloons in chronic total occlusion of the femoropopliteal arterial segment on the short-term course.

\section{PATIENTS AND METHODS}

A prospective randomized controlled comparative study was conducted in the Vascular Surgery Department, Aswan University Hospital during the period from March 2018 to March 2020. In 
total, 30 patients with a well-established diagnosis of superficial femoral artery (SFA) and/or proximal popliteal lesions with symptoms of PAD were included in the study respecting the inclusion and exclusion criteria.

\section{Patients were divided randomly into two groups:}

- Group A: Includes 15 patients who underwent simple percutaneous transluminal angioplasty.

- Group B: Includes 15 patients who underwent Drug coated balloons angioplasty.

Sample size: Thirty patients with chronic total occlusion of the femoropopliteal arterial segment (P1) admitted to the Vascular Surgery Department; Aswan University Hospital.

\section{Inclusion criteria:}

1. Patients with chronic total occlusion of the SFA or Fem-Pop segment with or without below the knee lesions (BTK) lesions.

2. Patients aged $40-75$ years

3. Symptomatic patient staged IIb, III, and IV Fontaine.

4. Diabetic ischemic patient.

5. Successful wire crossing of the lesion.

\section{Exclusion criteria:}

1. Concomitant proximal lesion.

2. Hepatic or renal patient.

3. Patients with heart failure.

4. Patients with poor life expectancy due to malignancy or terminal illness.

5. Patients with severe sepsis due to diabetic foot ulcers or wet gangrene.

6. Acute or sub-acute thrombus in the target vessel.

\section{All patients were submitted to the following:}

1-History: Personal data. Risk factors: smoking, DM, hypertension, hypercholesterolemia. Co-morbidity: heart failure, previous stroke, angina, MI. Prior procedures using femoral access and complications.

2-Physical examination, including Recording of peripheral pulses. Recording of signals using Doppler. Signs of chronic ischemia of the lower limb. Groin examination for signs of infection. Presence of Diabetic foot ulcer. Presence of dry or wet gangrene. Pressure measurements in the popliteal and ankle (ABI) are taken.

\section{3-Investigations:}

a) Laboratory: Routine biochemistry (Creatinine, estimated GFR, ESR, CRP, RBS, cholesterol,
HBA1c). Routine hematology (hemoglobin, white cell count, platelet count, HbA1c). PT, PTT, INR and lipid profile.

b) Noninvasive Imaging: Duplex ultrasound of bilateral lower limb arterial tree. X-ray for Diabetic foot ulcer.

c) Additional imaging modalities for all patients before intervention: $\mathrm{CT}$ angiography of infrarenal abdominal aorta and bilateral lower limb arterial tree.

Follow up: Clinical follow-up consisted of pulse examination and evaluation of the ulcer or amputation site healing or resolution of infection.

Clinical outcomes, primary patency, secondary patency, and complications following the procedure were reported. All patients were re-examined after one week to check for access site complications and to confirm patency.

All patients were followed for 12 months with regular visits at 1,6 and 12 months or when new complaints arise. Follow-up consisted of clinical examination \pm imaging study (duplex US every 3 months and CT angiography at first 6 months and by the end of the first year of the follow up) or if needed in cases of absent or diminished pulse or recurrence of symptoms.

Ethical approval and written informed consent: An approval of the study was obtained from Aswan University academic and ethical committee. Every patient signed an informed written consent for acceptance of the operation.

\section{Statistical analysis:}

Analysis was performed using the SPSS version 15 (Chicago, IL, USA). Results were presented as mean $\pm \mathrm{SD}$, range, numbers, and percentages. Continuous variables were compared with the unpaired t-test. Categorical variables were compared with Fisher's exact test or v2 test as appropriate. $\mathrm{P}<0.05$ was considered statistically significant.

\section{RESULTS}

In this study, 30 patients with chronic total occlusion of the Femoropopliteal artery, who underwent either Simple Percutaneous Transluminal Angioplasty (PTA) (15 patients, group 1) or Drugcoated balloons (15 patients, group 2) collected from the Vascular Surgery Departments, Aswan University Hospitals. 
Table 1: Demographic characteristics of the studied population.

\begin{tabular}{|c|c|c|c|}
\hline & $\begin{array}{l}\text { Group (1) } \\
\text { Simple } \\
\text { PTA } \\
(\mathrm{n}=15)\end{array}$ & $\begin{array}{c}\text { Group (2) } \\
\text { Drug-coated } \\
\text { balloons } \\
(\mathrm{n}=15)\end{array}$ & P-valud \\
\hline $\begin{array}{l}\text { Age (years), } \\
\text { Mean } \pm \text { SD } \\
\text { (range) }\end{array}$ & $\begin{array}{l}53 \pm 10.2 \\
(40-72)\end{array}$ & $\begin{array}{l}56 \pm 11.0 \\
(40-73)\end{array}$ & 0.444 \\
\hline \multicolumn{4}{|l|}{ Patient's Sex } \\
\hline Male & $10(66.7 \%)$ & $11(73.3 \%)$ & \multirow[t]{2}{*}{0.715} \\
\hline Female & $5(33.3 \%)$ & $4(26.7 \%)$ & \\
\hline \multicolumn{4}{|l|}{ Residence } \\
\hline Aswan & $10(66.7 \%)$ & $9(60.0 \%)$ & \multirow[t]{2}{*}{0.705} \\
\hline Others: & $5(33.3 \%)$ & $6(40.0 \%)$ & \\
\hline Abo-Sembl & $1(6.7 \%)$ & 0 & \\
\hline Dakka & 0 & $1(6.7 \%)$ & \\
\hline Draw & $1(6.7 \%)$ & $2(13.3 \%)$ & \\
\hline Edfu & $1(6.7 \%)$ & $1(6.7 \%)$ & \\
\hline Esna & 0 & $1(6.7 \%)$ & \\
\hline Garb Soheel & $1(6.7 \%)$ & 0 & \\
\hline Komombo & $1(6.7 \%)$ & $1(6.7 \%)$ & \\
\hline \multicolumn{4}{|c|}{ 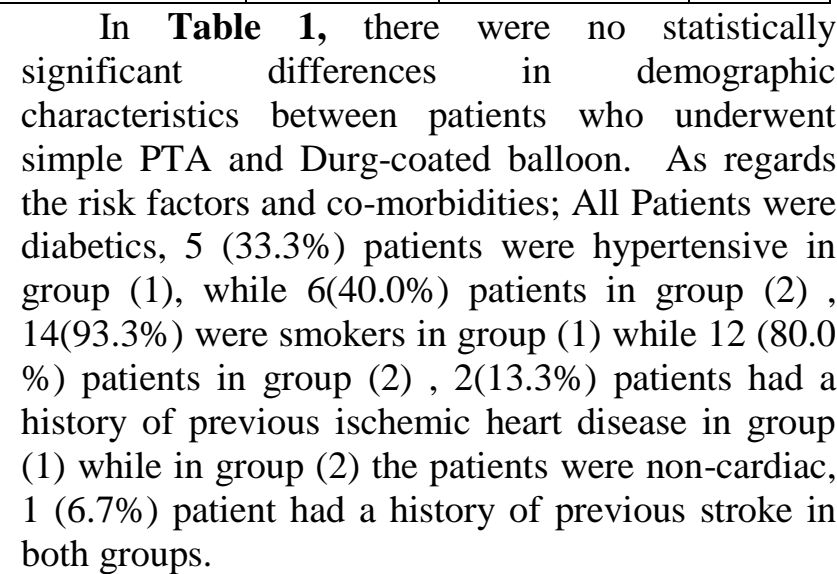 } \\
\hline
\end{tabular}

Table 2: Preoperative clinical characteristics and risk factors of the studied population.

\begin{tabular}{|c|c|c|c|}
\hline & $\begin{array}{l}\text { Group (1) } \\
\text { Simple PTA } \\
(\mathrm{n}=15)\end{array}$ & $\begin{array}{c}\text { Group (2) } \\
\text { Drug-coated } \\
\text { balloons }(\mathrm{n}=15)\end{array}$ & $\begin{array}{l}\text { P- } \\
\text { value }\end{array}$ \\
\hline \multicolumn{4}{|l|}{ Presentation } \\
\hline $\begin{array}{l}\text { Rutherford } \\
\text { category 3) } \\
\text { (fountaine IIb) }\end{array}$ & $3(20.0 \%)$ & $3(20.0 \%)$ & \multirow[t]{3}{*}{1.00} \\
\hline $\begin{array}{l}\text { Rutherford } \\
\text { category 4) } \\
\text { (fountaine III) } \\
\end{array}$ & $4(26.7 \%)$ & $5(33.3 \%)$ & \\
\hline $\begin{array}{l}\text { (Rutherford } \\
\text { category 5and 6) } \\
\text { (fountaine IV) }\end{array}$ & $8(53.3 \%)$ & $7(46.7 \%)$ & \\
\hline \multicolumn{4}{|l|}{ Smoking } \\
\hline Smokers & $14(93.3 \%)$ & $12(80.0 \%)$ & \multirow[t]{2}{*}{0.598} \\
\hline Non-smokers & $1(6.7 \%)$ & $3(20.0 \%)$ & \\
\hline \multicolumn{4}{|c|}{ Chronic Medical Conditions } \\
\hline Diabetes & $15(100 \%)$ & $15(100 \%)$ & 1.00 \\
\hline Hypertension & $5(33.3 \%)$ & $6(40.0 \%)$ & 0.705 \\
\hline $\begin{array}{l}\text { Ischemic Heart } \\
\text { Diseases }\end{array}$ & $2(13.3 \%)$ & 0 & 0.483 \\
\hline Previous Stroke & $1(6.7 \%)$ & $1(6.7 \%)$ & 1.00 \\
\hline
\end{tabular}

In Table 2, there were no statistically significant differences in clinical characteristics and risk factors between patients who underwent simple PTA and Durg-coated balloon.

There was a history of previous interventions; About $2(13.3 \%)$ patients had previous contralateral above-knee amputation (AKA) in each group. 2 $(13.3 \%)$ had a history of coronary artery stenting then $\mathrm{CABG}$ in group 1 more than 6 months ago

Table 3: Previous interventions among the studied population.

\begin{tabular}{|l|c|c|l|}
\hline & $\begin{array}{l}\text { Group (1) } \\
\text { Simple } \\
\text { PTA } \\
(\mathrm{n}=15)\end{array}$ & $\begin{array}{c}\text { Group } \\
(\mathbf{2}) \\
\text { Drug- } \\
\text { coated } \\
\text { balloons } \\
(\mathrm{n}=15)\end{array}$ & $\begin{array}{l}\text { P- } \\
\text { value }\end{array}$ \\
\hline $\begin{array}{l}\text { Previous } \\
\text { interventions }\end{array}$ & $2(13.3 \%)$ & 0 & 0.483 \\
\hline CABG & $2(13.3 \%)$ & 0 & 0.483 \\
\hline $\begin{array}{l}\text { Coronary artery } \\
\text { stenting }\end{array}$ & $2(13.3 \%)$ & $2(13.3 \%)$ & 1.00 \\
\hline $\begin{array}{l}\text { Contralateral } \\
\text { AKA }\end{array}$ & & & \\
\hline
\end{tabular}

In Table 3, there were no statistically significant differences in the history of previous interventions between patients who underwent simple PTA and Durg-coated balloon.

The lesion characteristics; $9(60.0 \%)$ patients were suffering from short lesions $(<10 \mathrm{~cm})$ in group 1 and $10(66.7 \%)$ patients in group $2.6(40.0 \%)$ patients were suffering from long lesions $(>10 \mathrm{~cm})$ in group 1 and $5(33.3 \%)$ patients in group 2.

All these lesions were chronic total occlusion (CTO) of the superficial femoral artery. Out of these patients; $8(53.3 \%)$ patients had multiple lesions in group 1 while $5(33.3 \%)$ patients in group (2).

Crossing lesion was subintimal in about 6 $(40.0 \%)$ cases in group 1 , while in $8(53.3 \%)$ cases in group 2. lesion were crossed intraluminally in 9 $(60.0 \%)$ cases in group 1 while $7(46.7 \%)$ cases in group 2.

About 9 (63.3\%) patients had multiple run off in group 1 while $8(53.3 \%)$ patients in group 2 .

About $6(40.0 \%)$ cases had single runoff in group 1 while 7 (46.7\%) cases in group 2 .

The access type used was either contralateral (retrograde) femoral access in $1(6.7 \%)$ patient and $2(13.3 \%)$ patients in group 1 and 2 respectively or ipsilateral (Antegrade) femoral access used in 14 (93.3\%) patients while $13(86.7 \%)$ patients in group 1 and group 2 respectively. 
Table 4: Lesion characteristics and Intraoperative data of the studied population.

\begin{tabular}{|c|c|c|c|}
\hline & $\begin{array}{c}\text { Group } \\
(1) \\
\text { Simple } \\
\text { PTA } \\
(n=15)\end{array}$ & $\begin{array}{c}\text { Group (2) } \\
\text { Drug- } \\
\text { coated } \\
\text { balloons } \\
(\mathrm{n}=15)\end{array}$ & $\begin{array}{l}P \text { - } \\
\text { value }\end{array}$ \\
\hline \multicolumn{4}{|l|}{ Access Type } \\
\hline Ipsilateral & $\begin{array}{c}14 \\
(93.3 \%)\end{array}$ & $13(86.7 \%)$ & \multirow[t]{2}{*}{1.00} \\
\hline Contralateral & $1(6.7 \%)$ & $2(13.3 \%)$ & \\
\hline \multicolumn{4}{|l|}{$\begin{array}{l}\text { Procedure- } \\
\text { related } \\
\text { complications }\end{array}$} \\
\hline None & $\begin{array}{c}14 \\
(93.3 \%)\end{array}$ & $13(86.7 \%)$ & \multirow[t]{2}{*}{1.00} \\
\hline $\begin{array}{l}\text { Non-flow } \\
\text { limiting } \\
\text { dissection }\end{array}$ & $1(6.7 \%)$ & $2(13.3 \%)$ & \\
\hline \multicolumn{4}{|l|}{ Lesion length } \\
\hline Short (<10c.m) & $9(60.0 \%)$ & $10(66.7 \%)$ & \multirow[t]{2}{*}{0.705} \\
\hline Long (>10c.m) & $6(40.0 \%)$ & $5(33.3 \%)$ & \\
\hline \multicolumn{4}{|l|}{$\begin{array}{l}\text { Number of } \\
\text { lesions }\end{array}$} \\
\hline Single & $7(46.7 \%)$ & $10(66.7 \%)$ & \multirow[t]{2}{*}{0.269} \\
\hline Multiple & $8(53.3 \%)$ & $5(33.3 \%)$ & \\
\hline \multicolumn{4}{|l|}{$\begin{array}{l}\text { Crossing } \\
\text { method }\end{array}$} \\
\hline Sub-intimal & $6(40.0 \%)$ & $8(53.3 \%)$ & \multirow[t]{2}{*}{0.464} \\
\hline Intraluminal & $9(60.0 \%)$ & $7(46.7 \%)$ & \\
\hline \multicolumn{4}{|l|}{ Run-Off Vessel } \\
\hline Single & $6(40.0 \%)$ & $7(46.7 \%)$ & \multirow[t]{2}{*}{0.713} \\
\hline Multiple & $9(60.0 \%)$ & $8(53.3 \%)$ & \\
\hline
\end{tabular}

In Table 4, there were no statistically significant differences in the intraoperative data between patients who underwent simple PTA and Drug-coated balloon.

The 30 patients were followed for 12 months for primary, secondary patency rates, and limb salvage rates were defined at 1, 6, 12 months.

The primary patency rates were $86.7 \%$, $66.7 \%, 46.7 \%$ at $1,6,12$ months respectively in group (1) Vs $100 . \%, 80.0 \%, 60.0 \%$ at $1,6,12$ months respectively in group (2), the patients didn't need any secondary procedures in the 1st month but secondary patency rates were $80.0 \%, 60.0 \%$ at 6,12 months respectively in group (1) Vs $100 \%, 73.3 \%$ at 6, 12 months respectively in group (2); Limb salvage was the same in both groups at $1^{\text {st }}$ month follow up; secondary procedures improved limb salvage rates at 6th month more in group (2); $93.3 \%$ than in group (1); $73.3 \%$; but at 12 th month the limb salvage rates were $66.7 \%$ in group (1) \& $86.7 \%$ in group (2).
Table 5: Postoperative patency rates among the studied population.

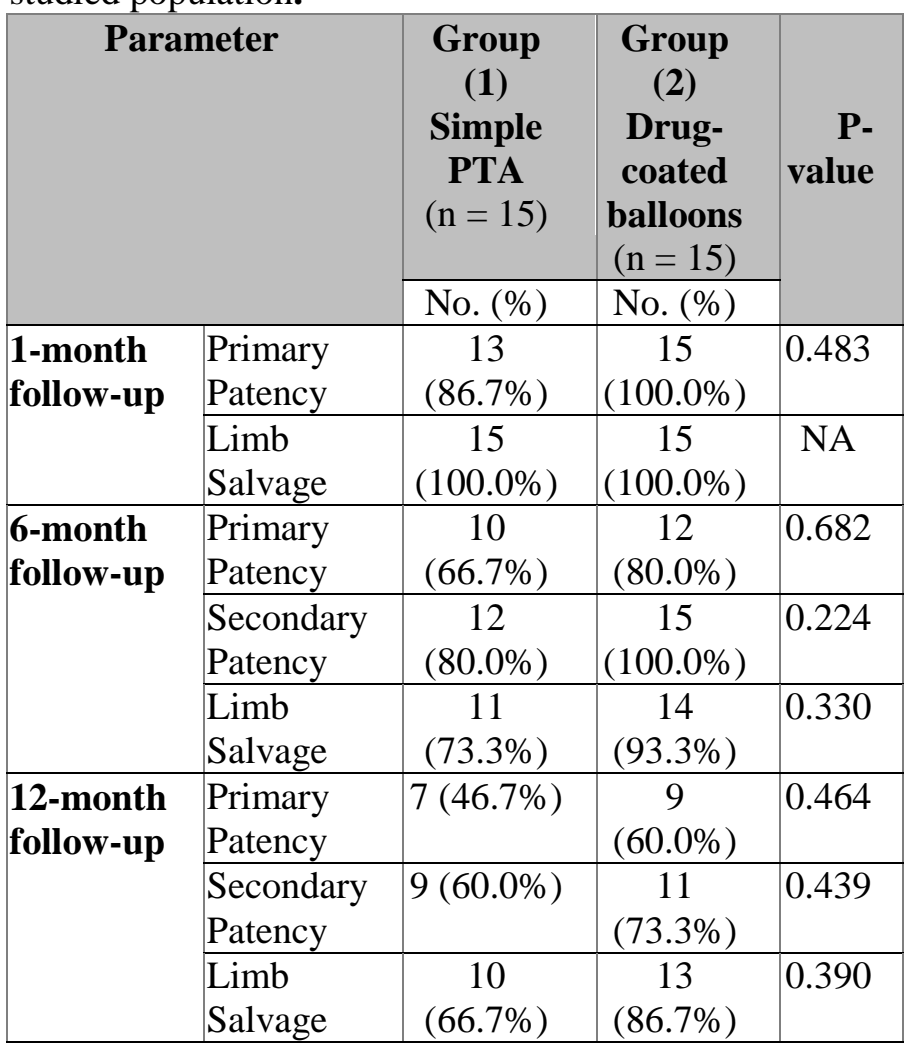

In Table 5, there were no statistically significant differences in the postoperative patency between patients who underwent simple PTA and Drug-coated balloon.

Between 1-6 months; 4 patients presented with a recurrent lesion, recurrent rest pain in 2 cases, and recurrent tissue loss (new tissue loss or failure of healing) in 2 cases. These 8 patients were distributed 5 cases in group (1) \& 3 cases in group (2); successful re-intervention by angioplasty was done in 2 patients of group (1) and by DCD in 3 patients of group (2).

In group (1) 3 patients had above knee amputation due to unsalvageable limb and 1 patient had below knee amputation due to spreading of infection despite successful re-intervention and presence of a popliteal pulse. In group (2) 1 patient had below knee amputation due to spreading of infection despite successful re-intervention and presence of a popliteal pulse.

At 12th month follow up; another 4 patients presented with recurrent symptoms and equally distributed in both groups; successful re-intervention by angioplasty and stenting was done in 1 patient and another one was corrected by bypass surgery while 1 patient died from myocardial infarction in group (1) but successful angioplasty by DCB was done in 1 case and one patient did not come for follow up in group (2). 
Table 6: Rate of clinically driven TLR in both groups.

\begin{tabular}{|l|c|c|l|}
\hline & $\begin{array}{c}\text { Group (A); } \\
\text { POBA }\end{array}$ & $\begin{array}{c}\text { Group (B); } \\
\text { DCB }\end{array}$ & P-value \\
\hline $\begin{array}{l}\text { Clinically- } \\
\text { driven TLR }\end{array}$ & $4(26.6 \%)$ & $4(26.6 \%)$ & $\mathrm{p}=1.0$ \\
\hline
\end{tabular}

\section{Safety and efficacy outcomes}

There was no procedure or death in either study group. The 12-month adverse effects, in term of all causes of device-related death $(\mathrm{N} .1=6.6 \% \mathrm{UCB}$ vs. $\mathrm{N} .0=\mathrm{DCB})$, minor amputation and debridement (N.3=20\% UCB vs. N.3=20\% DCB), and myocardial infarction (0\% UCB vs. N.1 $=6.6 \%$ DCB).

\section{DISCUSSION}

Until our submission, there are limited articles about CTO and long lesions with DCBs. Only the IN. PACT CTO study published in 2019 is focused on long and occlusive lesions and the DCBs ${ }^{(9)}$. But this is the first study including long and CTO femoropopliteal lesions based on the Asian population.

The IN. PACT CTO study with also $100 \%$ CTO lesions and $22.83 \mathrm{~cm}$ lesion length showed the primary patency is $88.7 \%(n=126)^{(9)}$.

Lai et al. ${ }^{(10)}$ reported primary patency to be $93.2 \% \pm 3.8 \%$ at 3 months, $88.3 \% \pm 4.9 \%$ at 6 months, $78.8 \pm 6.8 \%$ at 1 year in a single-arm trial including 44 femoropopliteal lesions (chronic total occlusion (CTO) plus $>10 \mathrm{~cm}$ ) treated with DCBs. The rate of freedom from TLR was $91.4 \pm 4.9 \%$ after 1 year.

Bosiers $\boldsymbol{e t}$ al. ${ }^{(11)}$ reported primary patency of $84.6 \%$ at 6 months and $71.1 \%$ at 1 year. Freedom from TLR was $79.9 \%$ at 1 year. This study was a prospective, multi-national, non-randomized, singlearm study evaluating the safety and efficacy of the Legflow paclitaxel-eluting balloon dilatation catheter in the treatment of stenotic or occlusive lesions $>150$ $\mathrm{mm}$ long in the femoropopliteal arteries of symptomatic patients (Rutherford 2-5). A total of 120 study subjects were enrolled.

Micari et al. ${ }^{(12)}$ reported 1-year primary patency in femoropopliteal lesions over $150 \mathrm{~mm}$ $(n=101)$ to be $83.2 \%$ while 1-year primary patency in complex femoropopliteal lesions (lesions over $10 \mathrm{~cm}$ or restenosis) was reported by Schmidt et $\boldsymbol{a l} .^{\left(\mathbf{1 3}^{\prime}\right)}$ as $79.2 \%$.

In comparison, 1-year patency rates of shorter lesions with DCBs range mainly from 85 to $90 \%$ (although some results are within 75-85\%) which is higher than that of long-lesion studies to some extent (14). This is probably because long lesions tend to cause a higher possibility of subintimal passage and losing more dose of paclitaxel in the passage. But since the difference is only $5-10 \%$, the availability of paclitaxel in longer lesions is also satisfactory ${ }^{(\mathbf{1 5})}$.

In our study evaluation was tried to assess the efficacy and safety of paclitaxel-coated balloon angioplasty versus POBA of symptomatic peripheral arterial disease of the femoropopliteal artery with CTO.

The salient findings were:

- The primary patency at 12-month following treatment with DCB was significantly better 100 . $\%, 80.0 \%, 60.0 \%$ at $1,6,12$ months compared with POBA $86.7 \%, 66.7 \%, 46.7 \%$ at $1,6,12$ months.

- The rate of clinically-driven TLR was the same in both groups (26.6\%)

- The use of DCB was safe and did not increase the major adverse clinical events (death, myocardial infarction, and minor or major amputation) when compared with those seen with the use of the uncoated balloons.)

The present study may be considered important as in our study we did not find a significant difference between both study groups in the clinicallydriven target lesion revascularization at 12 months follow-up. This is in contrast to the results of other DCB trials in which target lesion revascularization rates were significantly lower in the paclitaxel balloon group ${ }^{(16,17)}$.

The findings of better primary patency but no difference in cdTLR can be explained by several contributing factors. First, the sample size was small. Second, the healing response after arterial injury begins immediately after the angioplasty and may last for weeks or months, after that the cytotoxic drug paclitaxel has accomplished its action in the wall of the targeted artery.

Finally, the outflow of BTK-arteries (occlusive disease in the pedal arteries) was not assessed in our study.

Our results are also consistent with the LEVANT II trial - a single-blind, randomized trial of 476 patients compared Lutonix DCB- (Bard PV, Tempe, AZ, USA) with POBA-angioplasty for PAD - also failed to demonstrate a significant difference in the clinical improvement endpoints of target lesion revascularization at 12 months ${ }^{\mathbf{1 6})}$.

The results of our study do not provide definitive guidelines in managing PAD. We do agree that the studied patients' group was relatively small. Several trials have shown that after balloon angioplasty restenosis occurs in approximately $50 \%$ of cases within the first 6 months. The justification for this is that during this period the paclitaxel has to do its job (to inhibit the endothelial cell cycle in the $\mathrm{M}$ phase of the mitotic cycle). The IN. PACT SFA ${ }^{(16)}$, the LEVANT Rosenfield et al. ${ }^{(4)}$, and the debate-ISR Liistro et al. ${ }^{\left({ }^{(1)}\right)}$ trials have shown that the benefit of paclitaxel occurs during the first months after angioplasty. The Kaplan-Meier curves showed significantly better results at a 6-month follow-up, after this period the curves of DCB and UCB are approximately parallel. Furthermore, we studied a very sick patient population. 
A longer and repeatedly angiographic followup would be hazardous. DCB randomized trials of patients with inclusion of the below the knee arteries with a larger sample size \& with a longer follow-up period are necessary to (dis)prove our results.

\section{CONCLUSION}

This study focused on totally occlusive femoropopliteal arterial atherosclerotic treatment with POBA \& DCBs.

The determination of the best method of revascularization for the treatment of symptomatic peripheral arterial disease (PAD) is based upon the balance between the risk of a specific intervention and the degree and durability of the improvement that can be expected from this intervention.

The main reason for advocating endovascular treatment of the femoropopliteal segment (even if less durable compared to open surgery) is the low complication rate.

Use of DCBs is associated with improved vessel patency when compared to POBA in patients with FPD. There was no difference in clinically driven TLR between DCB and POBA in our study. Extended follow-up of the available RCT data will be essential to analyze long-term device-related mortality peripheral arterial occlusive disease.

\section{REFERENCES}

1. Tendera M, Aboyans V, Bartelink $M$ et al. (2011): ESC Guidelines on the diagnosis and treatment of peripheral artery diseases: document covering atherosclerotic disease of extracranial carotid and vertebral, mesenteric, renal, upper and lower extremity arteries. The Task Force on the Diagnosis and Treatment of Peripheral Artery Diseases of the European Society of Cardiology (ESC). Eur Heart J., 32:2851-2906.

2. Layden J, Michaels J, Bermingham S et al. (2012): Guideline development group. Br Med J., 345: 4947.

3. Armstrong E, Stephen W, Waldo S et al. (2016): Incomplete Revascularization Is Associated With an Increased Risk for Major Adverse Cardiovascular Events Among Patients Undergoing Noncardiac Surgery. American Colleague of Cardiology Foundation, 4:329 38.

4. Rosenfield K, Jaff M, White C et al. (2015): Trial of paclitaxel-coated balloon for femoropopliteal artery disease. N Engl J Med., 373: 145-143.

5. Scheinert D, Duda S, Zeller T et al. (2014): The LEVANT I (Lutonix Paclitaxel-Coated Balloon for the Prevention of Femoropopliteal Restenosis) Trial for Femoropopliteal Revascularization: First-in-Human Randomized Trial of Low-Dose Drug-Coated Balloon Versus Uncoated Balloon Angioplasty. JACC Cardiovasc Interv., 7:10-19.

6. Speck U, Cremers B, Kelsch B et al. (2012): Do pharmacokinetics explain persistent restenosis inhibition by a single dose of paclitaxel? Circ Cardiovasc Interv., 5:392-400.

7. Jaff M (2016): Drug-coated balloon treatment for patients with intermittent claudication: insights from the IN.PACT Global full clinical cohort. Paper presented at VIVA 16, the 14th Annual Vascular Inter Ventional Advances Meeting; Las Vegas, NV. Pp. 18-22.

8. Schroeder H, Meyer D, Lux B et al. (2015): Two-year results of allow -dose drug-coated balloon for revascularization of the femoropopliteal artery: outcomes from the ILLUMINATE first-in-human study. Catheter Cardiovasc Inerv., 86: 278-286.

9. Tepe G, Micari A, Keirse K et al. (2019): Drug-coated balloon treatment for femoropopliteal artery disease: the chronic total occlusion cohort in the IN. PACT global study. J Am Coll Cardiol Intv., 12(5):484-93.

10.Lai Z, Zhang X, Shao J et al. (2020): One-year results of drug-coated balloons for long and occlusive Femoropopliteal artery disease: a single-arm trial. BMC Cardiovasc Disord., 20(1):65-69.

11. Bosiers M, Deloose K, Torsello G et al. (2020): Oneyear outcome of the paclitaxel-eluting Legflow balloon catheter in the treatment of long and complex femoropopliteal lesions. J Cardiovasc Surg., 61:471-7.

12. Micari A, Vadalà G, Castriota F et al. (2016): 1-year results of paclitaxel-coated balloons for long femoropopliteal artery disease: evidence from the SFAlong study. J Am Coll Cardiol Intv., 9(9):950-6.

13.Schmidt A, Piorkowski M, Görner H et al. (2016): Drug-coated balloons for complex femoropopliteal lesions: 2-year results of a real-world registry. J Am Coll Cardiol Intv., 9(7):715-24.

14. Laird J, Schneider P, Tepe G et al. (2015): Durability of treatment effect using a drug-coated balloon for Femoropopliteal lesions. J Am Coll Cardiol., 66(21):2329-38.

15.Granada J (2018): Drug-Coated Balloons for In-Stent Restenosis: A Fierce Fight for a "Me-Too". Space, Pp. 2378-80.

16. Tepe G, Laird J, Schneider P et al. (2015): Drugcoated balloon versus standard percutaneous transluminal angioplasty for the treatment of superficial femoral and popliteal peripheral artery disease: 12-month results from the IN. PACT SFA randomized trial. Circulation, 131:495-502.

17. Werk M, Albrecht T, Meyer D et al. (2012): Paclitaxel-coated balloons reduce restenosis after femoropopliteal angioplasty: evidence from the randomized PACIFIER trial. Circ Cardiovasc Interv., 5:831-840.

18. Liistro F, Angioli P, Porto I et al. (2014): Paclitaxeleluting balloon vs. standard angioplasty to reduce recurrent restenosis in diabetic patients with in-stent restenosis of the superficial femoral and proximal popliteal arteries: The DEBATE-ISR study. Journal of Endovascular Therapy, 21(1): 1-8. 